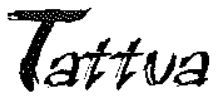

JOURNAL OF PHILOSOPHY

\title{
SUBJECTIVITY AND TRUTH
}

\author{
Jason W. Brown
}

\section{Introduction}

The interpretation of mental content in philosophy differs from that in process thought, particularly microgenesis, where the theory of the mental state is fundamental. In microgenesis, the direction of development and iteration of the mental state is from the core self to conscious mental content and external objects. Ideas, images, objects and feelings are individuations of the self that perish as momentary endpoints in a single act of thought or perception. Mental contents expose phases in the actualization. They do not lead to future acts but are replaced by ensuing ones. The relation of image to object, or of proposition to fact, is that of an intermediate to a distal phase in the same state, with intermediate and distal phases emanating from an antecedent phase of self. A fact is an outcome of conceptual-feeling, a mental object. Contents in the mental state are not themselves states. A proposition or image is not a mental state. The mental (mind/brain) state is the full process of actualization from core to content, from self to object. In clinical studies, symptoms are transiently exposed segments in mental process. The study of symptoms permits a reconstruction of the mental state that can serve as an anchor for speculation in neuroscience and psychology. 


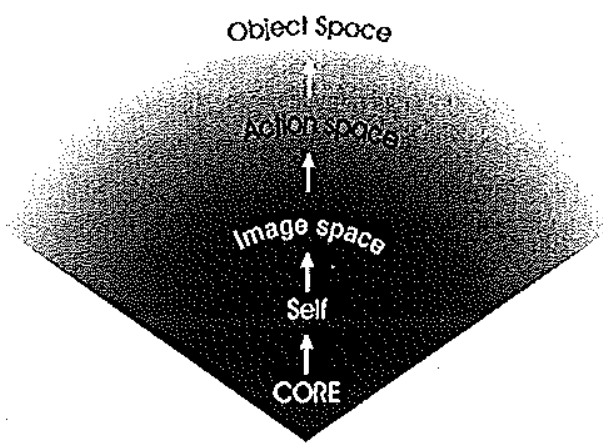

Legend: Transitional phases in the mind/brain state, from unconscious core, to self, to an intra-psychic space of imagery, to the external but still personal space of the body, to the extra-psychic space of objects. The fransifion from core to object world in an epoch of becoming is replaced by the ensuing state (see Brown, 2005 for discussion).

Externalism is outside the mental state, thus non-psychological. The primary relation is from a developed mental content, such as a proposition, to an objective fact. There is no mental thread from self to proposition, nor from proposition to fact, or if there is, it is conceived as inconsequential. The psychic antecedents of surface contents have no bearing on their interpretation. A proposition is distinct from its formative history, perceptions are "out there" in the world and reality is independent of thought. The truth of a proposition turns on the adequacy of the relation of mental to world events, but the mental events have already, in many instances; assumed the properties of external solids. Externalism uproots mental content from the psyche, displaces it to an abstract theatre in external space, and finally reinserts it into mind as a functional component. In the case of propositions, they are severed from mind, examined as to their truth-value, then transferred back into mind as instrumental in action. Externalism fabricates a theory of mind from the exposed objects of ordinary experience, whether logical solids such as propositions, or the constituents of concepts and perceptions, which are presumed ingredient in the objects into which they are assembled.

These differences between process and substance stem from such foundational issues as: (1) how do objects, as segments of events, precipitate in the mind (images, ideas) and in the world (objects), i.e., how are objects or mental contents carved out of flux, (2) why do we perceive objects, not the change that loys them down, including the transition from the self to its objects, and (3) how, in substance theory, does change occur across the sharp edges of object demarcations? 
Microgenetic theory requires on intuitive leap beyond direct experience. We see objects that change, not the change that deposits them. Objects are everywhere, motion is seamless, but change is invisible. The concepts of atomic or irreducible substance, instantaneous time and external relations, postulate change in the causal connectivity from one perceptual or logical solid to another. In process thought, objects arise in the replacement of epochs. Change is in the transition from potential to actual. The philosophy of becoming posits qualities; quantities, in contrast, are the currency of a philosophy of being. The accounts depend on competing theories of time and space. Are they irreconcilable, or can a substance ontology of being and external change be resolved with an event-ontology of becoming and intrinsic change?

Process theory appeals to its adherents for its subjectivism and tendency to idealism, while substance theory enlists support for its realism and objectivity. This is also a way of saying that externalism conforms to common sense, as in the idea of mind as a storehouse of feelings, memories and ideas, or the world as a collection of objects in causal interaction. The assembly model of perception and the copy theory of memory are derived from this way of thinking. The burden on process theory is to demonstrate the fiction of common sense beliefs when applied to the mind/brain, i.e., how such beliefs deceive us into thinking the mind is organized as a mirror of the world it displays. This burden is common to substance theory when mental objects, which are phases in actualization, such as the self, ore deemed illusory. If one holds that an object-like self that persists over time is an illusion - one of the most powerful we have - an account is needed of how it comes about, though it is probable that a thoughtful account of this problem would undermine the ordinary view of external objects. If the self is a category, so too are its derivations. If the self is an illusion, so are the mental and external objects to which it gives rise.

Not all distinctions are important, but importance can be given to any distinction. Once a distinction is made, it sheds its attachment to the ground from which it separated, and objectifies as an element or building block in the thought behind it. Organic wholes once divided are recombined as aggregates. Hume wrote that things distinguished are as separate as if there were no manner of connexion between them. A distinction justifies and propagates arguments on its behalf. With increasing definiteness and multiplication, inessential partitions obscure the deeper reality of antecedent wholeness. Artificial entities take on life in an artificial world, a parallel psychology or sphere of philosophical discourse. A computational model of the mind is the most obvious fiction, the main rationale for which, its presumed heuristic value, has a negative impact on direct study of the mind/brain. 
All internal and external objects are contrasts that achieve specificity at each phase in their derivation. Most of these phases are transitional and the confents are virtual; others are final and definite. All contents individuate out of neural configurations that have the potential to specity a number of alternative paths. The phase-transition is a series of whole-to-part shifts. Af each phase, the configuration is a matrix of possibilities. The succession of whole-part shifts exemplifies a fundamental law of the mind/brain that characterizes the transition from one phase to the next. The transition can also be described as a shift from potential to actual, but this is more aptly characterized as the trajectory of the entire process. This tendency to ever-greater individuation or analysis is the natural direction of thought, which leads ever further from the unity out of which partitions develop. In process theory, the individuation of objects in the mind/brain state illustrates the lawfulness of mental process. In substance theory, this lawfulness is replaced by entities in ad hoc relations dictated not by psychological necessity but by gaps in philosophical argumentation.

\section{Microgenesis and Pragmatism}

William James (1912) was close to the microgenefic concept of the mind/brain state in writing that: "whenever certain intermediaries are given, such that, as they develop towards their terminus, there is experience from point to point of one direction followed, and finally of one process fulfilled, the result is that their starting point thereby becomes a knower and their terminus an object meant or known".

In the description of overlapping pulses of consciousness he was also close to the microgenetic account of recurrence. The analogy would have been greater had he included the sculpting of phases by intrinsic habit and extrinsic sensations that shape the whole-part or context-item shifts to adapt personal need to conditions in the world. Put differenily, the sensory environment constrains the mind/brain state to eliminate maladaptive form. In art or poetry, truth rests on symbol, metaphor or allusion. This mode of truth-seeking has an affinily with the microgenetic account of intermediate phases in fact-creation. Shaping is incomplete; the greater subjectivity and inferioricity of early cognition come to the fore. In ordinary thinking, the content of a thought is achieved at the conclusion of the mental act. The object of the thought, and the agreement of thought with object, are outcomes of the state not evident at its inception.

There is a strong tendency, in the privacy and subjectivity of knowledge, for pragmatism and microgenesis to lead to ldealism. The adaptive nature of truthseeking implies the primacy of an individual perspective. The externalist links pragmatism to the opinion of a solitary thinker, rather than one who adjusts thought 
to an external standard. However, matching inner to outer or adjusting a personal truth to an external judgment is preconditioned on the existence of an external truth to which individual truth appeals, as well as the absolute or irrevocable nature of a truth that results from, or points to, a consensual judgment. External validation is the sum of individual judgments each of which is adaptive. Even if consensus is closer to "the truth", it is still provisional. To step outside all individual minds and compare an individual concept with God's perspective would entail a correspondence between individual or collective mind and mind-independent reality. It assumes access to the absolute reality of a physical world that is inaccessible to individual mind, which in any case would infect it with subjectivity. Put otherwise, if mind could know the physical world directly, that world would be altered in the very act of knowing it.

From an adaptive standpoint, individual truth is matched to the external by continuous revision. This occurs not by correspondence but the success in fitness and adjustment to the considered views of others. Except for stotes such as dream or hallucination, the world of perception is the only world we can perceive, for the sensory data coming from the world disallow alternalive, often maladaptive, possibilities. Thoughts and propositions that are realized in acts and statements are shaped to the world by reaction and conversation, in response to outer conditions and the behaviours of others. These influences are not resolutely "out there"; they offect individual mind by sculpting cognition to conditions to which it must adapt for the organism to survive and flourish.

The pragmatic or microgenetic theory of truth holds for observers up to the limit of evidence and a consensus beyond which, it is supposed, an absolute truth, outside consciousness and independent of human thought, is woiting to be discovered. Individual or consensual truth may resemble final truth, but unable to know the latter, it is a best approximation to the conditions to which it is applied. The lockedin mental world of a solitary mind, or a comparison to an external but unknowable physical world, implies an idealism at one extreme and/or an absolute reality at the other. Idealism does not obligate an absence of the external, but rather, a world that can only be known through a model, even if it is shaped so exactly that mind perceives its own product as "the real thing".

In microgenesis, every mind/brain state, every thought, percept or action, begins with implicit (unconscious) beliefs. When we perceive on object, the implicit belief inter alia is that an external world exists. When we have a thought or image, the implicit belief is a self that is thinking. An unconscious belief is the progenitor and guide to thought or action. The core self is derived from implicit belief, then specified to the conscious or empirical self, ideas, feelings and objects. A belief is not isolable from the self that believes. 
Belief is neither frue nor false. It is the agreement of belief with "reality" that determines truth. In having an internal and external segment, value is similar to belief. A perceived object selected by interest (Perry, 1926) is midway between implicit and explicit value (Brown, 2005). The internal aspect of value is desire; the external aspect is object worth. Beliefs and values are unconscious deferminants that can become conscious in thought or imagery, but the conscious belief is not a replica of that in the unconscious; it is an endpoint in a transition to consciousness in which proximal categories ore linked to distal ones by symbolic, metaphoric, experiential and affective relations.

\section{Conviction and Belief}

Errors are acts that do not adapt to the external and are correctible in ensuing revisions. An external standpoint is implied from the revision of an internal one. If error is thought to undermine pragmatism, trial-and-error resurrects it. The account of truth is weakened if the standard or standpoint outside the individual is absolute and independent of all thinkers. Each thinker undergoes a similar revision, carving out ideas to reach a consensus that a majorify of like-minded thinkers endorse. Truth is a matter of dispelling error to make room for fact. False beliefs are aides in coping, resilient, often magnets for reinforcement. The belief in God grows out of affective need, instilled values, early education, life-experience, the search for meaning, other phenomena, largely inexplicable, together with the complexity, obscurity and lack of signification of the everyday, as well as in reaction to scientific fact, which seems emply of personal value. A powerful emotional experience, or one instilled by trauma or "brainwashing", can induce conviction in false belief. False beliefs such as the Capgras delusion (see below) or the beliefs of a primitive mentality are unshakeable. For example, Levy-Bruhl (1975) described a tribe, the Bororo that cannot be convinced by arguments that another tribe, the Trumai, do not pass the night under water.

Such fixed beliefs have adaptive value in serving to explicate unknown realms of psychic or natural experience into which observation and objectivity have not yet ventured. A false belief that a person can outrun a tiger - or is imbued with tigerspirit - might help him to escape, while a rational acceptance that the belief is untrue entails waiting to be devoured. One acts according to conviction regardless of its truth. To believe is not the same as to know. One says, I believe there is a God, nol I know there is a God. One can say, I do not know bul I believe. True knowledge is the unacknowledged subtext of thought, but belief is its engine.

In a false belief or delusion such os the Capgras syndrome, a spouse, close friend or relative is mis-identified.' This disorder is "modularized" by cognitivists who, 
ignoring the context and full description of the disorder, maintain that it points to an isolated belief system. But a false belief is not an island of mentation. Such cases offen have other reduplications, e.g., their home, altered feeling in the double, e.g., a seducer, age regression, e.g., the double may be younger, and the belief is not resistant to manipulation by the examiner. Even psychotic delusions can be altered by suggestion. In conversion hysteria, correcting one false belief, e.g., a limb paralysis, may lead to another even worse, e.g., blindness. The claim of modularity follows from the divisibility or logical substantiality of encapsulated psychic phenomena, which are postulated as autonomous so as to conform abnormal psychology to philosophy and to models of normal cognition, when such perturbations should be the data from which a robust philosophy could be extracted.

Russell distinguished the psychological question, what makes us hold a belief is true, from the philosophical question, what is it for a belief to be true. What makes us hold a belief is true can be construed as the capacity to distinguish true and false belief. This reflects the structure of a belief and the reasons why we believe it to be true. Action is driven by conviction, certainty is hesitant. I can be certain that pastrami will give me indigestion or that a certain movie will cause a headache, yet l eat the pastrami and see the film. Someone who believes a house is haunted will probably not enter it. Superstition and magical belief are manifestations of a preliminary phase of syncrefic thinking in normal people (Brown, 2000; 2005). The conviction in false belief, in myth, delusion and primitive mentality, are not distortions of the normal but markers of the paralogical thinking that underlies rational thought.

Conviction leads to action, certainty tends to be provisional. Certainty implies knowledge supported by reason with an openness to refutation, and has an impersonality that conviction rejects. One can be certain of a thing, but then realize that you were mistaken. Conviction does not depend on proof or demonstration, but on values that underlie belief and the coherence with other beliefs and past experience. Moore wrote of rock-bottom beliefs such as this is my hand, yet amputees with phantoms have a hard time believing, with the eyes closed, that the hand is not there. Patients with autotopagnosia with a lesion in the parietal lobe and intact limbs may locate their hand on the wall! Pathological case study reminds us of the vulnerability of so-called rock bottom beliefs based on certain knowledge, of the self, of the existence of the world, even that one is alive.

What makes a person hold a belief is true involves factors other than its truth. Strong conviction is absolute in its truth; it may coincide with truth but does not require it. A belief in heaver and hell, angels and devils, obsessions and delusions, with no evidence of truth and much to deny it, exert a powerful effect on reason. Unlike conviction, certainty does not tolerate an incompatibility of belief. When 
conviction conflicts with fact or other beliefs, true or false, or when, from an objective standpoint, one belief contradicts another, the opposing beliefs retain their force through shared aftributes or conjoined properties that override incompatibilities. A shared property or predicate leads to the identification of disparate topics instead of a resemblance of topics in respect of that property (Brown, 2000).

What gives a belief conviction is not whether it is right or true, since conviction is often stronger for beliefs that are evidently false or untestable. The strength of conviction accompanies a resistance to falsification. Conviction replaces the need for choice and decision. It is closer to drive, desire and the core self, often bound up with the self-concept, rooted in unconscious bias and the seeds of action. Truth for the psyche is the adaptation of need to circumstance. The transition from deeper, more personal concepts and feelings to rational ones depends on the degree to which the sensory environment shapes the emerging thought, i.e., the strength of endogenous concepts versus adaptive pressures. These pressures carry the concept to the external world, to greater impersonality and concessions to others. The dominant focus of an act of thought determines whether a belief is fixed and delusional, scientific and provisional, or a philosophical truth that depends on the agreement of generic propositions with timeless objects. What if is for a belief to be true engages less the bases of truth-demonstration than the conditions on which truth is decided. Ultimately, this depends on the agreement of belief with fact, though facts depend on other beliefs so there must be coherence within belief systems for any given belief to be decided as true.

For psychology, it is less how my belief relates to the external situation and more how if relates to what I know and feel. Conviction seizes on facts that satisfy innate, early-acquired, unconscious or implicit beliefs. The implicit beliefs that guide conviction are saturated with feeling and deep in individual character and personality, while the explicit beliefs that guide abstract or rational thought are surface articulations of these constructs in which feeling and valuation have been decanted. The certainty one will defend is not the conviction one will die for. Though conviction in a false belief is occasionally given up when reason prevails, rarely does conviction - as opposed to certainty - follow on rational deliberation.

We should recall that in most instances, expediency is the mother of truth. The context behind a fact is too vast for the whole truth to be taken into account. To say, this is a cup of tea, supposes one comprehends the language and has an intact perceptual system, that one knows what tea is and can distinguish it from other liquids, that one knows a cup and can distinguish it from a bowl, saucer and other such items, that one comprehends the other (object, person) in relation to the self, and can access an object-concept out of wider spheres of self and world knowledge. 


\section{Adaptation and Correspondence}

Utility is an adjustment of inner to outer, or the fitness of concept to fact, which is the adaptation of mind to an inferred external world. Truth is conformity to an external sifuation. Trivially, this implies that truth is what works in a given circumstance. The locality of utility is in tension with the generality of its application, for a conditional or provisional truth in pragmatism, or in science, even if it has a relative ubiquity of application, is not perceived as eternally true. The question is whether pragmatism is an inadequate theory for philosophy, or whether philosophy must adjust its fruthclaims to psychological reality.

The correspondence of content with reality and the adaptation of content to reality are linked ideas. The ideal of philosophical truth is an agreement (adaptation) of mind and nature that is universally and forever true. Psychological truth approaches philosophical truth when an adaptation holds on repeated occasions. The difference is the imperfection of truth-finding in psychology (and science) and the absoluteness of truth-knowing in philosophy. If there are such timeless truths - logical, mathematical - invariant, applicable to the very large and very small, to mind and world, experience and thought, then the provisional truths of psychology are a continuous working-toward them.

In logic, the direction from idea to reality prevails over that from thinker to thought, though to begin with reality, which is the tendency in analytic and empirical thinking, as in common sense, and move inward to thought, is the reverse of the direction of thought itself. The reality that shapes thought is the reality thought creates. The former is that of physical sensation applied to thought as a limit, the latter, a mental picture (or sound, touch) that results from on iterated trimming of endogenous form. To common sense, a picture of the world is the starting point of thought, not its outcome, but for internalism (or microgenesis), intra- and extra-personal contents are outcomes. The content that externalism maps to reality, and the reality to which that content corresponds, are phases in a single mind/brain state. The irony is that truth in externalism depends on a correspondence between two false beliefs: the reification of mental content and the reality and autonomy of its objectifications.

Along these lines, the externalist concept of the aboutness of intentionality as a direction to a mental or external object can be seen as a relation of penultimate to final phases in a mind/brain state. Introspective content is intermediate in the actualization, not a terminal addition (Brown, 1996). The fonward direction and the analysis or individuation over phases narrows intra-psychic potential to exirapsychic definiteness. A relative suspension of sensory constraint allows thought to deposit at pre-terminal phases, e.g., imagination, fantasy, reverie. With loss of 
constraint, in dream, hallucination and psychosis, thought moves outward (or the world recedes). The transition is from felt experience to observation, from gestalt to figure, from generality to precision. In this progression, the mind achieves conformity to an experiential niche that is a negative image of the real.

Given the opposition of internal and external perspectives, neither of which are decisive, one perspective ought not to prevail at the other's expense, since a metaphysic probably owes more to the unconscious presuppositions of the thinker than the logic behind them (Collingwood, 1940). Moreover, either approach is incomplete without the other. From an internal standpoint, the relation of self to content gives truth limited by personal need. From an external standpoint, with the self left behind and distal phases sliced off, truth is the correspondence of earlier to later in a single state. Comprehensiveness demands the incorporation of all phases in the state, and a sincere effort to deal with feeling in decision-making and objectvalue and, more generally, the affective tonality of supposedly affect-free concepts.

It is worth noting a similarity in the relation of idea and object to that of recall and a standard in memory. In the former, correspondence is across distal phases in consciousness. In the latter, it is from an unconscious phase to a conscious one. If a concept arrives at fruth when if matches an object, does a memory arrive at precision when experience matches recall? In one instance, a conscious mental content is compared with a physical reality on the other side of perception. In the other, a conscious mental content is compared with the physical reality of the unconscious. In truth-seeking, thought, memory and the objects before us all realize the potential behind them striving for completeness.

\section{Process, Content and Truth}

An external object requires a subject as observer but an internal or psychic object requires a self. All mental contents are conscious. The rest is non-conscious process, whether intra- or extra-psychic. The becoming of a conscious object is the dynamic through which the mental state takes on existence, i.e., phases that generate the subjectivity of an object (or entity). For internalism, truth depends on the realization of veridical objects, as well as coherence at each phase in fact-creation. Externalism assumes self-sufficiency, stability and persistence. The concordance of thought to fact, or logical to perceptual objects, has one (logical) foot in the psyche, the other (perceptual) foot in the physical world. The description from outside treats some psychic contents, e.g. propositions, as objective, others not, e.g., hallucinations. Diachronic process goes from unconscious to conscious, past to present, potential to actual; synchronics goes from one conscious actuality to another. 
A thought can be a vague idea, a specific idea of an object, or the object the idea is about. ${ }^{2}$ Thinking of a horse, the idea is imminent in the perception, even if a horse suddenly comes into view without thinking about it. The horse is recognized as it is seen. It is judged to be beautiful or ordinary, approachable or dangerous. Concepts and feelings are activated with the initial perception. The object (horse) individuates meanings and feelings that are part of its structure. In ordinary perception, concepts relinquished in a transition to the object endure in the perception as identification, import and affective charge. The ideo or concept of a horse, and the horse, objectify successive phases - from intra- to extra-psychic - in a common process.

A statement, such as "that is a horse", or the depiction of a horse in a drawing, points to an object beyond the words or marks. Signs that stand for or point to objects are said to have a derived intentionality from the meanings behind them. In that an objectified content-word, drawing - designates an object, it is presumed to be intentional. On this view, the mental content is interprefed as intentional rather than the trajectory from the self to that content. But drawing a horse, a unicorn or the Guernica is the outcome of a series of mental states. The object depicted in the drawing - real, imaginary or an art-work - develops out of an idea. It is not a further object to which the drawing refers, since the referent, present or not, is also derived from the mental state. The horse in the fields that is named or called, or rendered in a drawing, is an extra-personal image that has developed out of an object-concept. The fact that phases in qualitalive transformation take on greater substantiality in their outward development makes us think that we copy a real horse, not a picture of a real horse in the external space of mind, in which a drawing and a horse individuate a common ground.

For externalism, the mind produces or discovers facts that are mind-independent. For microgenesis (and pragmatism), facts are creations, irreducible values as Dewey put it. Since perceptual objects are products of the mind, the internalist tends to infer a physical ground, an absolute reality that is independent of observation and beyond human experience. The absolute and the eternal are palliatives for incessant loss in a theory of flux. This tendency is less pronounced in externalism where permanence is endemic and the distinction of object and entity is blurred.

\section{Intentionality}

A good example of snatching mental contents from the mind as philosophical objects is found in the literature on intentionality, in which propositional contents are detached, analyzed and reinserted in the mental state as adjudicative in choice 
and action. Intentional objects lifted from the psyche and re-introduced as determinative in judgment require o consinual of truth as determining the intentionality of the act it subtends. The procedure is confused because two mental acts are postulated, that of thinking about something, which is the act of believing or having a thought, and that of believing the thought is true. An act of speculative thought as to the truth of the belief is postulated to supplement a genuine act of agency, i.e., believing, desiring, intending, etc. ${ }^{3}$

Confusions arise when the object of a thought is interpreted in terms of its content, especially its propositional content, and the glide from the content to the impact of truth-attributions on action. This is sharply drawn in the writings of Davidson (1980) on intentionality, where it is claimed that intentionality requires background rationality or, put differently, intentionality can only be ascribed to rational acts that are based on the truth of statements about them. Davidson's example is a person who spills a cup of tea thinking it is coffee. The claim is that the infentional act of spilling coffee becomes non-intentional when the coffee is discovered to be tea, though the spilling can still be an act of agency. Here, the act of truth-reconciliation is appended to a prior act, which substifutes for belief a true fact that relates to world knowledge. If true knowledge can retroactively negate or call into question the intentional quality of a prior act, would this not apply even if the agent were unaware of the contents of the cup? The act of thought in which others know the cup contains tea is devoid of psychological import, though the knowledge, if available to the agent, can become part of subsequent intentions.

If the outcome of an action - spilling coffee instead of tea - has retroactive force in altering intentionality, at what point is the outcome fixed? Take a hypochondriac who believes he has cancer. Were one to falsity the belief, that might not alleviate the hypochondriasis nor alter his conviction. The doctors are wrong, or have overlooked the correct diagnosis. Suppose he develops cancer some years later. How does this rebound on the intentionality of his prior thoughts or acts? If a person gives money to help someone but the money winds up, instrumentally, in the hands of an assassin, at what point does the later outcome cease to influence the intentionality of the original act? An intentionality hostage to truth requires many qualifications. Most statements are not clearly or immediately true and what is true of a statement at one time may differ at another.

Mistaken attributions do not influence the psychological quality of action. An act based on true knowledge is identical to one based on error, since the knowledge guiding the act is the same in both cases. If I believe I can reach an apple in a tree but fail in my attempt, how does the error in belief affect the act? Were I to truly believe I could not reach the apple, I would not reach for it, and there would be no 
act of reaching to which a judgment of intentionality would be applied. This raises the problem that a judgment of intentionality in such an instance based on a true proposition would, if known and accepted beforehand, result in a failure to act, so there would be no act based on false belief, save inaction, to which the truth determination applies.

Assuming that the quality of an action is independent of whether the knowledge accompanying the action is true or false, it is obvious that most individuals have incomplete knowledge of the true nature of their objects, whether they believe a ticket will win the lottery or that to marry your true love brings lasting happiness. If an act does not differ if the agent believes it is based on true knowledge that furns out not to be the case, as in the usual example of Polonius, or a husband who kills his wife believing, falsely, she is unfaithful, what is the utility of arguments from the standpoint of truth attributions?

To replace the psychology of actions with judgments of the truth of propositions about them presumes a degree of certainty as to the truth. If the cup contains tea instead of coffee, what sort of tea, how strong, how hot? Tea is a super-ordinate category. How much has to be known about the object for the action to be intentional? Must one know or say, I am spilling a three-quarter cup of mild, luke-warm Darjeeling? If the individual believes he is spilling a liquid without knowing the type, or merely inverting a cup without knowing the contents, how does his knowledge impact on the intentionality of his actions? If an error in the identification of an object vitiates intentionality, what degree of precision is required to restore it? If the act of spilling coffee or tea does not differ according to the truth of the actor's beliefs, how can the knowledge of on observer influence its intentionality? This takes intentionality outside the agent, and turns the psychology of the intentional into a discourse on linguistic or semantic aftributions? Is this what Brentano had in mind? Is the intentional fundamental to conscious thought or is it a meta-theory about the words used to describe it?

If the intentionality of an act is determined by the truth of a belief or if intentionality depends on the beliefs of others as to the aim or content of the action, how and by whom is the intentional to be decided? If another person's knowledge of an action can decide whether or not an act is intentional, what aspect of the intentionality of an act is determined by factors outside it? The extemal perspective entails a consensus as to the content of the actor's mind even if the act is identical across conflicting judgments. Absent the truth-judgments of others, is it possible for a person to act infentionally in isolation, or to know whether or not his acts are intentional? is it not odd to maintain that one acts as an agent, while others decide whether or not the act is intentional? This implies that the judgment of the intentionality of an act is 
another act in the mind of the actor, or an act in the mind of an observer. But these external and ancillary acts are open-ended regressions that can also be submitted to a judgment of their intentionality, i.e., the statement that a proposition is true or false is itself a true or false statement. This implies that the determination of intentionality is not by means of a secondary act appended to the primary one, but can only be decided within the act itself and by the actor, though it can be inferred by an observer.

Another consequence of the dual-act argument is that it supposes the opposite condition, namely, that a person can either mistakenly believe his act is intentional, or unknowingly act intentionally. Such examples show the difficulties that accrue when the intrinsic nalure of the act, i.e., the correlated mental state, is replaced by descriptions based on the truth of statements about it. The displacement from privileged access transforms a direct account of action - voluntary, agentive, intentional, involuntary, automatic, or other acts of thought and perception - to a decision on the truth of statements about the content of an actor's mind. More precisely, the description of an action is removed to a shared field of propositions distinct from the intrinsic states they purport to describe. The cure for this distortion is for the intentional to be transported from the truth of an external committee to a subjective aim in the mind of an individual.

It seems obvious that a content in the mind such as a proposition, or in the world such as a chair, manifests an unseen internal process of composition or formation. This process, the momentary pre-history of the content, is conceived as physical with respect to the chair in its mechanical or atomic structure, and physiological or psychic with respect to the mind, in brain activity or a combination of memorial and perceptual features. A strictly physical theory entails that an object is the sum of the parts from which it is constructed and into which it decomposes, for example, the way a chair or sentence is physically put together. On this view, assembly does not count in what an object is. The process that generates an object or statement is like the manufacture of a car, which is conceived as independent of the order in which it was assembled. From the internal standpoint, the world and its objects are wholes. From an external standpoint, objects are aggregates. Externalism liberates mental events from their antecedents, crops them into objects, and transfers them to a world of substance, creating entities at the forward edge of causal efficacy.

There is one world, not a choice between an immaterial psyche and a mindless nature, but a nature that is compatible with psychology. A theory of becoming is the key to the unification of internal and external perspectives. If becoming in mind and nature does not deposit entities but constifutes them, to demarcate the actual as content and neglect the antecedent as assembly is like describing the flow of a 
river with bricks. The tendency to extend mechanism to the psyche and not expand the psyche to the external leads to a machine theory of organism. This tendency is reinforced by the rupture of a graduated aim to definiteness by the uncoupling of late phases from early ones, or subtracting the early ones from their outcomes, when all phases participate in the epoch of every object or idea.

Finally, substantialism is related to instantaneity. If instants are discrete, so are substances. Whitehead (PR 20) asked, "How can concrefe fact exhibit entities abstract from itself and yet participate in by its own nature". I take this to mean, how does nature enter (participate in) entities that are abstractions of the mind? The reply is that modeling is an adaptation to nature in which flux is anchored by abstractions of time and space, i.e., epochs of process create objects from overlapping durations. The specification of fact from initial generality is exposed in the suppression of the irrelevant. The context sampled at successive phases in the mental state, with the impact of nature at every phase, is one aspect of the totality to which Whitehead referred.

\section{Notes:}

1. See my description of a Capgras case (Franklin, Brown and Freedman, 1982).

2. Object and confent are here used interchangeably. From o psychological standpoint, the distinction is arbitrary. The real divide is between the object (or content) and the process that actualizes the object. The content of an object, e.g. a horse depicted in a painting, the painting, the aclual horse, ils toil or a tear in the convos, merely rellecis the immediate focus of attention, which is the object or content of the momentary consciousness.

3. See the crilique by Sprigge (Pulnam, 1997) who, along the lines of this argument, postulates one act of conceiving o state of offairs that includes belief in its actuality.

\section{Reference:}

1. J. W. Brown, Microgenelic theory: reflections and prospects, Neuropsychoanalysis, $3(2001): 61-74$.

2. J. W. Brown, Mind and Noture: Essays on Time and Subjeclivity (London: Whurr, 2000).

3. J. W. Brown, Process and the Authentic Life (Ontos: Heusenstamm, 2005).

4. R. Collingwood, An Essay on Metophysics (Oxford: Clarendon Press, 1940).

5. D. Davidson, Essays on Actions and Events (Oxford Universily Press, 1980).

6. G. Franklin, J.W. Brown, and M. Freedman, (1982) Capgras syndrome a deux. Lancel 2:222.

7. W. James, Principles of Psychology. (New York: Henry Holt \& Co., 1890).

8. James, Essays in Radical Empiricism (New York: Longmans, Green \& Co., 1912), P. 57-58. in Sprigge, p. 138. 
9. Levy-Bruhl, L. The Notebooks on Primitive Mentality. (Blackwell, Oxford, 1949/1975).

10. Perry, R. B., General Theory of Valve, New York, Longmans, Green, 1926.

11. Schweiger, A. and Brown, J.W. Minds, Models and Modules. Aphasiology, 2:531-543,1989.

12. Sprigge, T. James, aboutness and his British critics. In : R. Pulnam (Ed) The Cambridge Companion to William James, (Combridge University Press, 1997), 125-144.

13. Sprigge, T. The Phenomenalogy of Thought, in press, (2009).

14. Whitehead, A. Process and Reality. Edited by D. Griffin and D. Sherburne. Free Press, (1978ed). 